Article

\title{
Study on Nanofibrous Catalysts Prepared by Electrospinning for Methane Partial Oxidation
}

\author{
Yuyao Ma, Yuxia Ma, Min Liu, Yang Chen, Xun Hu, Zhengmao Ye and Dehua Dong *
}

School of Materials Science and Engineering, University of Jinan, Jinan 250022, China; snsdyoona530@163.com (Y.M.); jndx_yxma@163.com (Y.M.); lm970222@163.com (M.L.); cy0204Yyqx@163.com (Y.C.); Xun.Hu@outlook.com (X.H.); mse_yezm@ujn.edu.cn (Z.Y.)

* Correspondence: mse_dongdh@ujn.edu.cn; Tel.: +86-531-8973-6011

Received: 4 April 2019; Accepted: 17 May 2019; Published: 23 May 2019

\begin{abstract}
Electrospinning is a simple and efficient technique for fabricating fibrous catalysts. The effects of preparation parameters on catalyst performance were investigated on fibrous $\mathrm{Ni} / \mathrm{Al}_{2} \mathrm{O}_{3}$ catalysts. The catalyst prepared with $\mathrm{H}_{2} \mathrm{O} / \mathrm{C}_{2} \mathrm{H}_{5} \mathrm{OH}$ solvent showed higher catalytic activity than that with $\mathrm{DMF} / \mathrm{C}_{2} \mathrm{H}_{5} \mathrm{OH}$ solvent because of the presence of $\mathrm{NiO}$ in the catalyst prepared with $\mathrm{DMF} / \mathrm{C}_{2} \mathrm{H}_{5} \mathrm{OH}$ solvent. The metal ion content of the precursor also influences catalyst properties. In this work, the $\mathrm{Ni} / \mathrm{Al}_{2} \mathrm{O}_{3}$ catalyst prepared with a solution containing the metal ion content of $30 \mathrm{wt} \%$ demonstrated the highest Ni dispersion and therefore the highest catalytic performance. Additionally, the Ni dispersion decreased as calcination temperature was enhanced from 700 to $900{ }^{\circ} \mathrm{C}$ due to the increased Ni particle sizes, which also caused a high reduction temperature and low catalytic activity in methane partial oxidation. Finally, the fibrous $\mathrm{Ni} / \mathrm{Al}_{2} \mathrm{O}_{3}$ catalysts can achieve high syngas yields at high reaction temperatures and high gas flow rates.
\end{abstract}

Keywords: electrospinning; fibrous catalysts; metal ion content; calcination temperature; methane partial oxidation

\section{Introduction}

Electrospinning has been developed to fabricate one-dimensional materials with controllable fiber diameters, morphologies and compositions. Electrospun nanofibers have special features, such as hierarchically porous structure and high surface area, which have been successfully applied in various fields such as nanocatalysts, filtration, biomedical, optical electronics and electrodes for energy conversion or storage devices [1-5].

$\mathrm{Ni} / \mathrm{Al}_{2} \mathrm{O}_{3}$ fibrous catalysts prepared by electrospinning have applied in catalytic methane reforming $[1,6,7]$. Ni nanoparticles can be in situ formed on the nanofiber surface via reducing catalyst precursor $\mathrm{NiAl}_{2} \mathrm{O}_{4}$. The fibrous structure of the catalysts is stable up to $1000{ }^{\circ} \mathrm{C}$ [6]. Moreover, the fibrous structure has a large void fraction (about 95\%), which enables operation at high gas hourly space velocities through catalyst bed. It matches with the fast reaction of methane partial oxidation, which can be completed within a contact time of sub-milliseconds $[8,9]$. Therefore, the fibrous catalysts can produce high syngas yields [1].

Catalyst precursor solution greatly affects the electrospinning process via viscosity and evaporation [2]. To the best of our knowledge, the effect of preparation parameters on electrospun catalyst has not been reported previously. This study has investigated the effects of solvent, metal ion content and calcination temperature on catalyst properties, including crystallinity, particle size, microstructure, reducibility and catalytic performance. The preparation parameters were optimized to achieve high performance of methane partial oxidation (POM). The effects of reaction parameters on catalyst properties was also studied to utilize the advantages of fibrous catalysts. 


\section{Experimental}

\subsection{Catalyst Preparation}

The fibrous $\mathrm{Ni} / \mathrm{Al}_{2} \mathrm{O}_{3}$ catalysts were prepared by electrospinning, and the electrospinning process was started with preparing a spinning solution. A certain amount of polyvinyl pyrrolidone (PVP, molecular weight $=1.3 \times 10^{6}$, Shanghai Dibo Chemical Technology Co., Ltd., Shanghai, China) was dissolved in $2.0 \mathrm{~g} \mathrm{C}_{2} \mathrm{H}_{5} \mathrm{OH}$ ( $\geq 99.7 \mathrm{wt} \%$, Sinopharm Chemical Reagent Co., Ltd., Shanghai, China) and $8.0 \mathrm{~g} \mathrm{H}_{2} \mathrm{O}$ to prepare a PVP solvent. $\mathrm{Al}\left(\mathrm{NO}_{3}\right)_{3} \cdot 9 \mathrm{H}_{2} \mathrm{O}(\geq 99.0 \mathrm{wt} \%$, Sinopharm Chemical Reagent Co., Ltd., Shanghai, China) and $\mathrm{Ni}\left(\mathrm{NO}_{3}\right)_{2} \cdot 6 \mathrm{H}_{2} \mathrm{O}(\geq 99.0 \mathrm{wt} \%$, Sinopharm Chemical Reagent Co., Ltd., Shanghai, China) were dissolved in the solvent to form the catalyst with the Ni content of $30 \mathrm{wt} \%$ in $\mathrm{Ni} / \mathrm{Al}_{2} \mathrm{O}_{3}$, and the Ni content was same for all catalysts. The electrospinning solutions with different metal ion contents are denoted $C X(X=10,20,30$ and 40$)$, where $X$ represents the metal ion content, defined as solute (nitrate) weight percentage in precursor solution (solute + solvent). The ratio between solvent and solute in the C10, C20, C30 and C40 catalysts was 8.7:1, 4:1, 2.2:1 and 1.5:1, respectively.

Electrospinning was conducted on a device (Ucalery ET-2535H, Beijing, China) with a spinning distance of $30 \mathrm{~cm}$ driven by a applied voltage of $19 \mathrm{kV}$. The feeding rate was maintained at $0.05 \mathrm{~mm}$ $\mathrm{min}^{-1}$. The sample was calcined at $800^{\circ} \mathrm{C}$ for $1 \mathrm{~h}$ in air.

The effect of solvents was compared by using the catalysts with $20 \mathrm{wt} \%$ metal ion content. Only $\mathrm{H}_{2} \mathrm{O}$ in the solvent was changed to DMF $(\geq 99.5 \mathrm{wt} \%$, Sinopharm Chemical Reagent Co., Ltd., Shanghai, China), and the weight ratio to distilled water was 4:1. Other preparation parameters are the same. In addition, the catalyst prepared with a metal ion content of $30 \%$ was calcined at 700,800 and $900{ }^{\circ} \mathrm{C}$, separately, to study the effect of calcination temperature on catalyst properties.

\subsection{Catalyst Characterisation}

Scanning electron microscopy (SEM) images of catalyst microstructure were acquired with a FEI QUANTA FEG 250 microscope. Crystal sizes were measured using an X-ray diffractometer (XRD, Bruker D8 Advance) with $\mathrm{Cu}-\mathrm{K} \alpha$ radiation $(\lambda=0.15408 \mathrm{~nm}$ ). Temperature-programmed reduction (TPR) was conducted on a Micrometric ChemiSorb 2720 using a $10 \mathrm{mg}$ of catalyst and a feeding gas of $10 \mathrm{vol} \%$ $\mathrm{H}_{2}$ in Ar with a gas flow rate of $30 \mathrm{~mL} \mathrm{~min}^{-1}$. The TPR tests were operated from room temperature to $1000^{\circ} \mathrm{C}$ at a heating rate of $10^{\circ} \mathrm{C} \mathrm{min}{ }^{-1}$. CO-chemisorption was performed on a Micrometric ChemiSorb 2720 using a $30 \mathrm{mg}$ of catalyst. First, the catalyst was reduced by the TPR process. Next, the catalyst was cooled to room temperature for pulse chemisorption using $5 \mathrm{vol} \% \mathrm{CO}$ in $\mathrm{He}$.

\subsection{Catalytic Reaction}

The calcined catalysts were crushed into sheets about $900 \mu \mathrm{m}$ in size to ensure the similar density of catalyst beds. Catalytic evaluation was tested in a fixed bed quartz tube reactor (inner diameter $=$ $6 \mathrm{~mm}$ ) with a central K-type thermocouple. $10 \mathrm{mg}$ of the catalyst was pre-reduced in situ by $10 \mathrm{vol} \% \mathrm{H}_{2}$ in $\mathrm{Ar}$ at $750^{\circ} \mathrm{C}$ for $1 \mathrm{~h}$. The reactant gas of $\mathrm{CH}_{4}, \mathrm{O}_{2}$ and $\mathrm{Ar}$ with a molar ratio of 2:1:17 was introduced into the reactor at $750{ }^{\circ} \mathrm{C}$ at a gas flow rate of $800 \mathrm{~mL} \mathrm{~min}^{-1}$. Reaction products were sampled by a gas chromatography (GC, Shimadzu GC-2014).

\section{Results and Discussions}

\subsection{Effect of Solvent}

A solvent is used to dissolve catalyst precursors and polymer, forming electrospinning solution. During the electrospinning, the solvent needs to be evaporated before electrospun fibrous composites reach collectors so as to retain fibrous morphology. Solvent properties affect solution viscosity and solvent evaporation. Therefore, two common solvents, $\mathrm{H}_{2} \mathrm{O} / \mathrm{C}_{2} \mathrm{H}_{5} \mathrm{OH}$ and $\mathrm{DMF} / \mathrm{C}_{2} \mathrm{H}_{5} \mathrm{OH}$, are employed to investigate the solvent effect. Both catalysts had a metal ion content of $20 \mathrm{wt} \%$ and were calcined at $800^{\circ} \mathrm{C}$ for $1 \mathrm{~h}$. 


\subsubsection{XRD}

Figure 1 shows the XRD patterns of the catalysts prepared with different solvents. The catalyst prepared with the $\mathrm{H}_{2} \mathrm{O} / \mathrm{C}_{2} \mathrm{H}_{5} \mathrm{OH}$ solvent has no $\mathrm{NiO}$ diffraction peaks while the catalyst prepared with the $\mathrm{DMF} / \mathrm{C}_{2} \mathrm{H}_{5} \mathrm{OH}$ solvent shows $\mathrm{NiO}$ peaks, indicating Ni segregation during electrospinning. The segregation might be caused by the solubility difference of two metal ions in the two solvents. $\mathrm{Ni}\left(\mathrm{NO}_{3}\right)_{2} \cdot 6 \mathrm{H}_{2} \mathrm{O}$ has a lower solubility in the $\mathrm{DMF} / \mathrm{C}_{2} \mathrm{H}_{5} \mathrm{OH}$ than the $\mathrm{H}_{2} \mathrm{O} / \mathrm{C}_{2} \mathrm{H}_{5} \mathrm{OH}$, while $\mathrm{Al}\left(\mathrm{NO}_{3}\right)_{3} \cdot 9 \mathrm{H}_{2} \mathrm{O}$ has the similar solubility in the two solvents (Table 1). The lower solubility of $\mathrm{Ni}\left(\mathrm{NO}_{3}\right)_{2} \cdot 6 \mathrm{H}_{2} \mathrm{O}$ in the $\mathrm{DMF} / \mathrm{C}_{2} \mathrm{H}_{5} \mathrm{OH}$ causes the segregation during drying electrospun fibrous composites. The phase segregation also resulted in the higher crystallinity of $\mathrm{NiAl}_{2} \mathrm{O}_{4}$ and $\mathrm{Al}_{2} \mathrm{O}_{3}$. After reduction, Ni presents in both catalysts while the catalyst prepared with the $\mathrm{DMF} / \mathrm{C}_{2} \mathrm{H}_{5} \mathrm{OH}$ solvent shows the larger $\mathrm{Ni}$ crystal sizes due to $\mathrm{NiO}$ reduction.
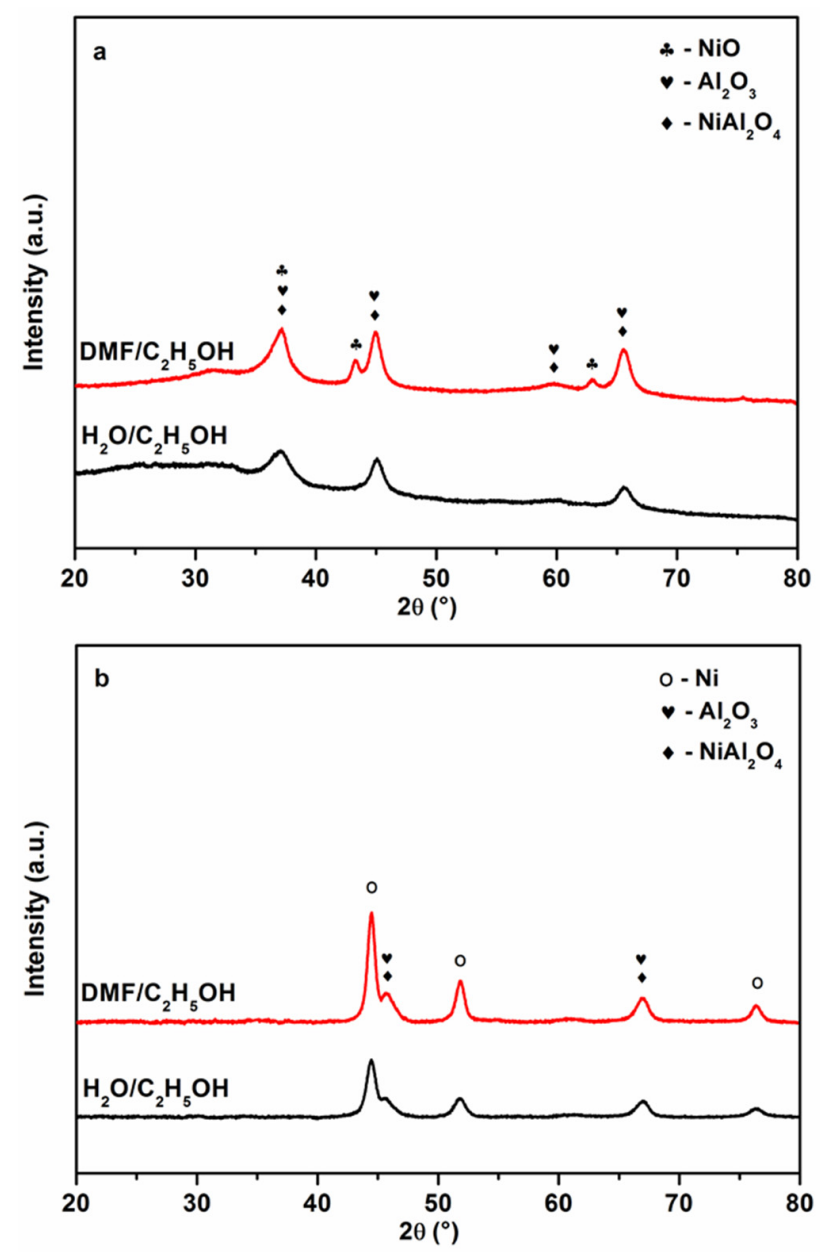

Figure 1. XRD patterns of the catalysts with different solvents: (a) Before reduction; (b) after reduction at $750{ }^{\circ} \mathrm{C}$ for $1 \mathrm{~h}$.

Table 1. Solubility of nitrates in two solvents.

\begin{tabular}{ccc}
\hline Solvent $(\mathbf{8} \mathbf{g} / \mathbf{2} \mathbf{~ g})$ & $\mathbf{N i}\left(\mathbf{N O}_{3}\right)_{\mathbf{2}} \cdot \mathbf{6 \mathbf { H } _ { 2 }} \mathbf{O}(\mathbf{g})$ & $\mathbf{A l}\left(\mathbf{N O}_{3}\right)_{3} \cdot \mathbf{9} \mathbf{H}_{\mathbf{2}} \mathbf{O} \mathbf{( g )}$ \\
\hline $\mathrm{DMF} / \mathrm{C}_{2} \mathrm{H}_{5} \mathrm{OH}$ & 24.5 & 18.5 \\
$\mathrm{H}_{2} \mathrm{O} / \mathrm{C}_{2} \mathrm{H}_{5} \mathrm{OH}$ & 35.5 & 19.5 \\
\hline
\end{tabular}

\subsubsection{SEM}

The morphologies of the reduced catalysts prepared with different solvents are presented in Figure 2. The fibrous structure has high void fraction and therefore achieves fast mass transfer [10]. 
Figure 2a shows the morphology of the catalyst prepared with the $\mathrm{H}_{2} \mathrm{O} / \mathrm{C}_{2} \mathrm{H}_{5} \mathrm{OH}$ solvent, uniform Ni particles anchored on the surface of fibrous support. As shown in Figure 2b, some large Ni particles appeared on the catalyst surface prepared with the $\mathrm{DMF} / \mathrm{C}_{2} \mathrm{H}_{5} \mathrm{OH}$ solvent, which was attributed to $\mathrm{NiO}$ reduction.
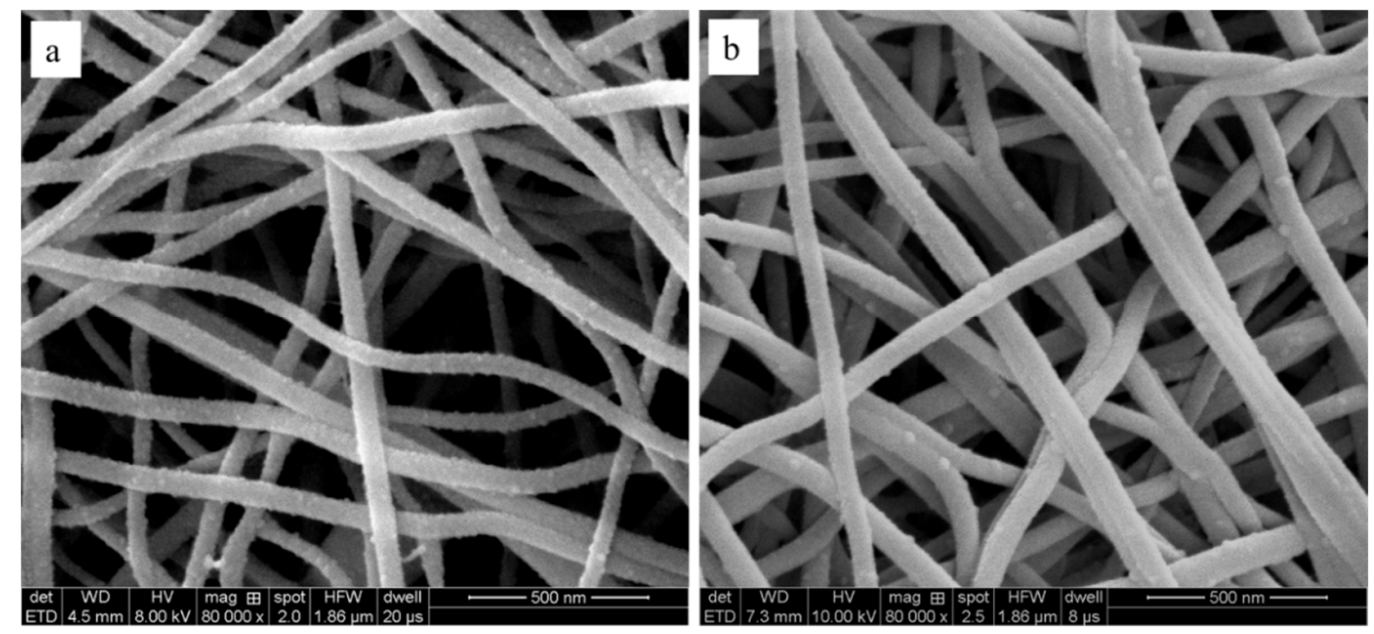

Figure 2. SEM images of the reduced catalysts prepared with different solvents: (a) $\mathrm{H}_{2} \mathrm{O} / \mathrm{C}_{2} \mathrm{H}_{5} \mathrm{OH}$; (b) $\mathrm{DMF} / \mathrm{C}_{2} \mathrm{H}_{5} \mathrm{OH}$.

\subsubsection{TPR and CO-Chemisorption}

TPR was carried out on fibrous catalysts to investigate reducibility. Figure 3 shows that the TPR profiles of the catalysts consist of two reduction peaks centered at 500 and $800{ }^{\circ} \mathrm{C}$, respectively. $\mathrm{NiO}$ reduction occurs at low temperatures $\left(400-600^{\circ} \mathrm{C}\right)$ while $\mathrm{NiAl}_{2} \mathrm{O}_{4}$ reduction takes place at temperatures above $600{ }^{\circ} \mathrm{C}[6,11]$. For the catalyst prepared with the $\mathrm{DMF} / \mathrm{C}_{2} \mathrm{H}_{5} \mathrm{OH}$ solvent, the $\mathrm{NiO}$ reduction peak is stronger than the catalyst prepared with the $\mathrm{H}_{2} \mathrm{O} / \mathrm{C}_{2} \mathrm{H}_{5} \mathrm{OH}$ solvent. The $\mathrm{H}_{2}$ consumption peak areas and reducibilities are compared in Table 2. The reducibility of the catalyst prepared with the $\mathrm{DMF} / \mathrm{C}_{2} \mathrm{H}_{5} \mathrm{OH}$ solvent is lower than that of the catalyst prepared with the $\mathrm{H}_{2} \mathrm{O} / \mathrm{C}_{2} \mathrm{H}_{5} \mathrm{OH}$ solvent. It might be attributed to $\mathrm{Ni}$ segregation because the $\mathrm{Ni}$ segregation causes $\mathrm{NiO}$ aggregation on the fiber surface, and the formed large $\mathrm{NiO}$ particles cause a decrease in reducibility. In addition, the $\mathrm{Ni}$ dispersion of the catalyst prepared with the $\mathrm{DMF} / \mathrm{C}_{2} \mathrm{H}_{5} \mathrm{OH}$ solvent is smaller than that of the catalyst prepared with the $\mathrm{H}_{2} \mathrm{O} / \mathrm{C}_{2} \mathrm{H}_{5} \mathrm{OH}$ solvent (Table 2) because the large Ni particles formed by $\mathrm{NiO}$ reduction decrease the $\mathrm{Ni}$ dispersion.

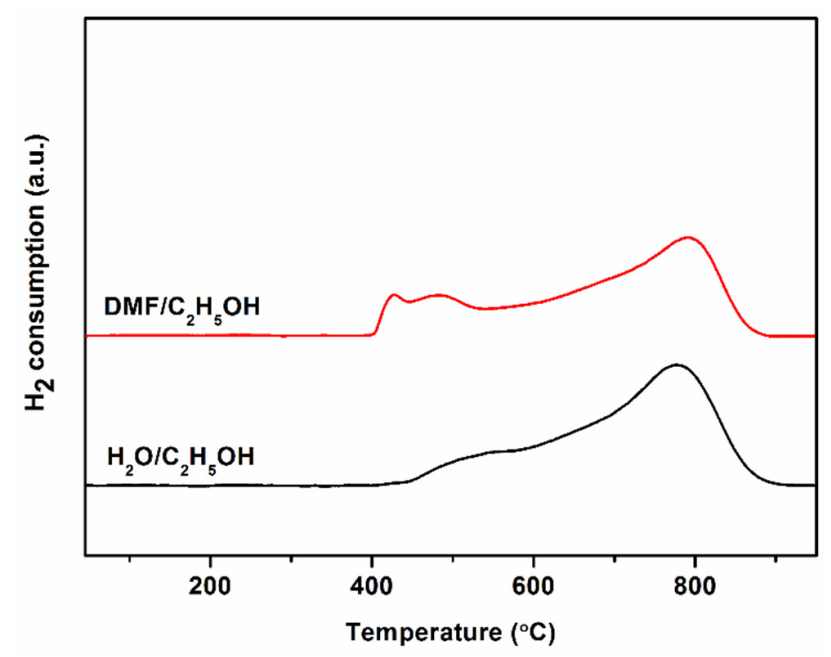

Figure 3. TPR profiles of the catalysts prepared with different solvents. 
Table 2. Reducibility and $\mathrm{Ni}$ dispersion of $\mathrm{Ni} / \mathrm{Al}_{2} \mathrm{O}_{3}$ catalysts.

\begin{tabular}{cccc}
\hline Sample & Peak Area & Reducibility (\%) & Ni Dispersion (\%) \\
\hline $\mathrm{DMF} / \mathrm{C}_{2} \mathrm{H}_{5} \mathrm{OH}$ & 48.3 & 76.6 & 0.05 \\
$\mathrm{H}_{2} \mathrm{O} / \mathrm{C}_{2} \mathrm{H}_{5} \mathrm{OH}$ & 51.6 & 83.4 & 0.27 \\
\hline
\end{tabular}

\subsubsection{Catalytic Performance}

Figure 4 shows catalyst performance during methane partial oxidation at $750{ }^{\circ} \mathrm{C}$ and a gas flow rate of $800 \mathrm{~mL} \cdot \mathrm{min}^{-1}$. The catalyst prepared with the $\mathrm{DMF} / \mathrm{C}_{2} \mathrm{H}_{5} \mathrm{OH}$ solvent generated a low methane conversion of about $10 \%$, which degraded rapidly. According to the TPR results of the spent catalysts in Figure 5, a substantial amount of Ni particles in the catalyst prepared with the DMF/ $\mathrm{C}_{2} \mathrm{H}_{5} \mathrm{OH}$ solvent were oxidized into $\mathrm{NiO}$ during the POM. In contrast, there is no obvious $\mathrm{NiO}$ reduction peak in the catalyst prepared with the $\mathrm{H}_{2} \mathrm{O} / \mathrm{C}_{2} \mathrm{H}_{5} \mathrm{OH}$ solvent as the fresh catalyst. Our previous study shows the catalytic activity is mainly contributed by $\mathrm{Ni}-\mathrm{NiO}_{x}$ particles formed from $\mathrm{NiAl}_{2} \mathrm{O}_{4}$ reduction rather than $\mathrm{Ni}$ particles formed from $\mathrm{NiO}$ reduction. Therefore, the catalyst prepared with the $\mathrm{H}_{2} \mathrm{O} / \mathrm{C}_{2} \mathrm{H}_{5} \mathrm{OH}$ solvent demonstrated a high and stable methane conversion of $30 \%$, which is consistent with the results of Ni dispersion in Table 2.

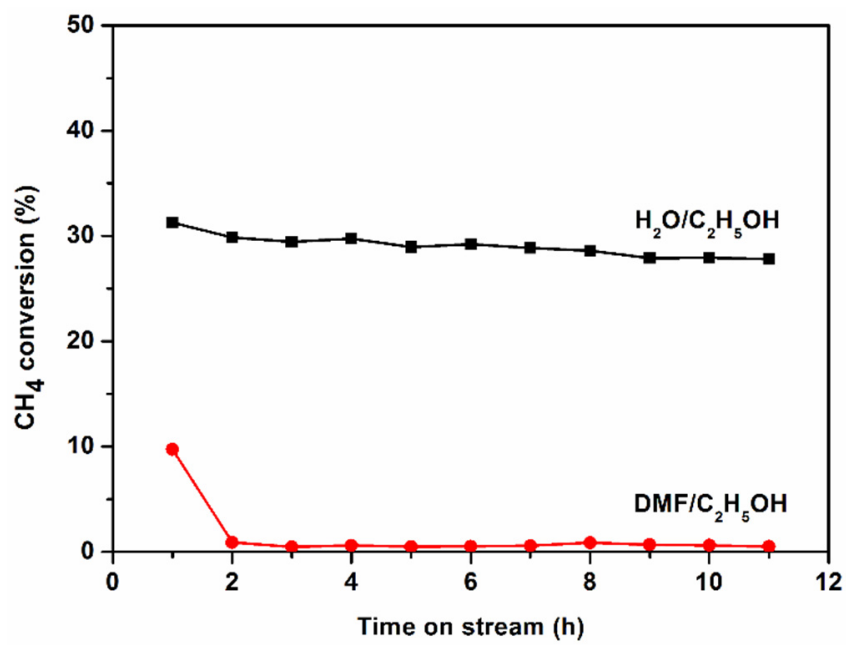

Figure 4. Methane conversion of the catalysts prepared with different solvents during the POM $10 \mathrm{~h}$ at $750{ }^{\circ} \mathrm{C}$ and a gas flow rate of $800 \mathrm{~mL} \cdot \mathrm{min}^{-1}$.

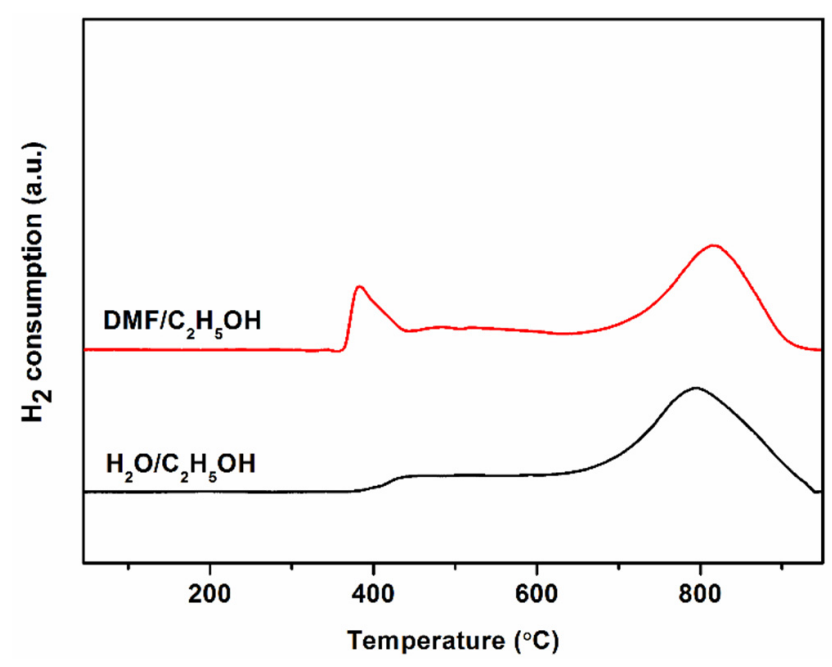

Figure 5. TPR profiles of the spent catalysts prepared with different solvents. 


\subsection{Effect of Metal Ion Content}

During electrospinning, electrical filed force pulls solution drop from spinneret to form a jet. Metal ion content affects solution viscosity, electrical filed force and final ceramic fibers. Therefore, the effect of metal ion content was investigated. All catalysts were prepared with the $\mathrm{H}_{2} \mathrm{O} / \mathrm{C}_{2} \mathrm{H}_{5} \mathrm{OH}$ solvent and calcined at $800{ }^{\circ} \mathrm{C}$ for $1 \mathrm{~h}$.

\subsubsection{XRD}

Figure 6 exhibits the XRD patterns of the catalyst prepared with different metal ion contents. As the metal ion content is increased, $\mathrm{NiO}$ phase started to present, indicating $\mathrm{Ni}$ segregation. It is because Ni prefers to accumulate on the surface in $\mathrm{NiO}-\mathrm{Al}_{2} \mathrm{O}_{3}$ system $[12,13]$. As shown in Figure 6a, calculated using the Scherrer equation, the $\mathrm{NiAl}_{2} \mathrm{O}_{4}$ crystal sizes of the $\mathrm{C} 10, \mathrm{C} 20, \mathrm{C} 30$ and $\mathrm{C} 40$ catalysts are 9.7, 8.5, 8.0 and $7.5 \mathrm{~nm}$, respectively. The $\mathrm{NiAl}_{2} \mathrm{O}_{4}$ crystal sizes decrease as the metal ion content is increased, which is because $\mathrm{NiO}$ presence dispersed $\mathrm{NiAl}_{2} \mathrm{O}_{4}$ phase, inhibiting $\mathrm{NiAl}_{2} \mathrm{O}_{4}$ growth. After reduction, Ni peaks are observed in addition to the $\mathrm{NiAl}_{2} \mathrm{O}_{4} / \mathrm{Al}_{2} \mathrm{O}_{3}$ peaks.
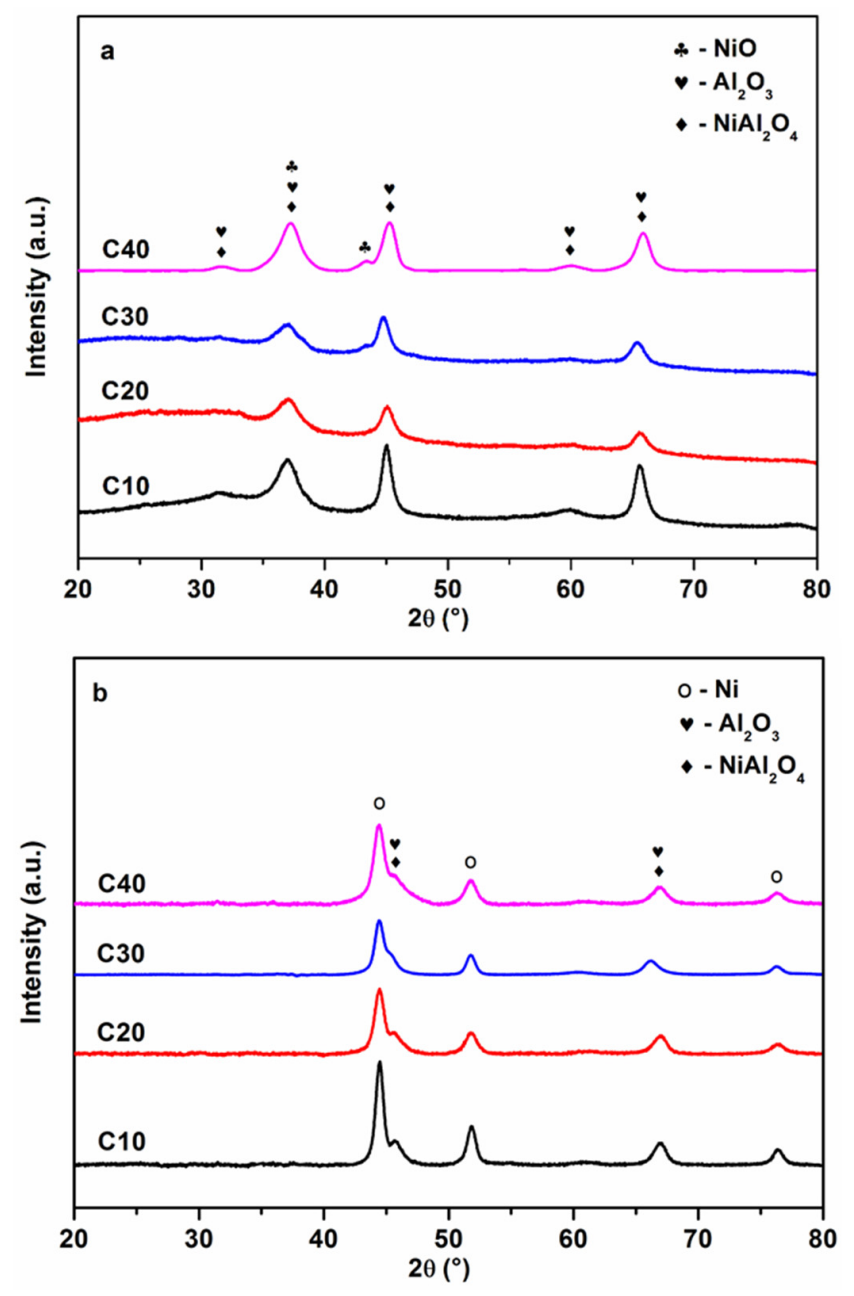

Figure 6. XRD patterns of the catalysts with different metal ion contents: (a) Before reduction; (b) after reduction at $750{ }^{\circ} \mathrm{C}$ for $1 \mathrm{~h}$.

\subsubsection{TPR and CO-Chemisorption}

As shown in Figure 7, for the $\mathrm{C} 10$ catalyst, a single $\mathrm{NiAl}_{2} \mathrm{O}_{4}$ reduction peak was centred at $800{ }^{\circ} \mathrm{C}$. When metal ion content was increased to $20 \mathrm{wt} \%$, the reduction peak occurs around $400{ }^{\circ} \mathrm{C}$, which is attributed to $\mathrm{NiO}$ reduction. The $\mathrm{H}_{2}$ consumption peak areas and reducibilities are summarized in 
Table 3. As the metal ion content is increased, the amount of reduced $\mathrm{NiO}$ increases, indicating more $\mathrm{NiO}$ segregated. Therefore, the reducibility of fibrous catalysts also increases. Furthermore, the Ni dispersion increases with metal ion content up to $30 \mathrm{wt} \%$. However, the Ni dispersion of the C40 catalyst is reduced because of $\mathrm{NiO}$ aggregation [14]. Therefore, a certain amount of $\mathrm{NiO}$ can improve Ni dispersion.

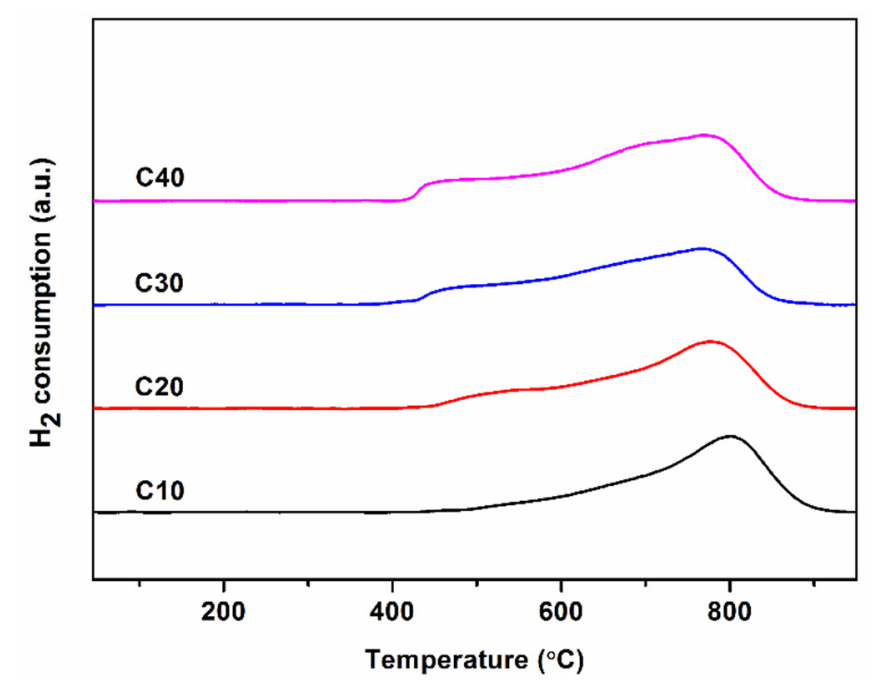

Figure 7. TPR profiles of the catalysts prepared with different metal ion contents.

Table 3. Reducibility and $\mathrm{Ni}$ dispersion of $\mathrm{Ni} / \mathrm{Al}_{2} \mathrm{O}_{3}$ catalysts.

\begin{tabular}{cccc}
\hline Sample & Peak Area & Reducibility (\%) & Ni Dispersion (\%) \\
\hline C10 & 50.8 & 81.7 & 0.17 \\
C20 & 51.6 & 83.4 & 0.27 \\
C30 & 52.7 & 85.7 & 0.60 \\
C40 & 57.4 & 95.4 & 0.39 \\
\hline
\end{tabular}

\subsubsection{SEM}

The morphologies of reduced catalysts made from the solution prepared with different metal ion contents are shown in Figure 8. The fiber diameter increases with the increase of metal ion content from 50 to $300 \mathrm{~nm}$ due to the increased solution viscosity and metal ion loading. Ni particles present on fiber surface after reduction. The $\mathrm{C} 10$ catalyst shows the largest $\mathrm{Ni}$ particle sizes, and Ni particle sizes increase when metal ion content was increased from 20 to $40 \%$. The change of Ni particle sizes are consistent with the change of crystal sizes in Figure 6a, and the large crystal sizes generate the big Ni particles.

\subsubsection{Catalytic Performance}

The fibrous catalyst prepared with different metal ion contents were tested for the POM at $750{ }^{\circ} \mathrm{C}$ and a gas flow rate of $800 \mathrm{~mL} \mathrm{~min}^{-1}$ to investigate catalytic activity. As shown in Figure 9, methane conversion improves with metal ion content up to $30 \mathrm{wt} \%$, and further increasing metal ion content to $40 \mathrm{wt} \%$ causes a decline in $\mathrm{CH}_{4}$ conversion. The catalytic performance is consistent with Ni dispersion in Table 3, and the higher dispersion contribute the higher catalytic performance. In addition, the $\mathrm{Ni}$ particles formed by $\mathrm{NiO}$ are easily oxidized during the $\mathrm{POM}$, which has the limited contribution to catalytic performance [14]. 

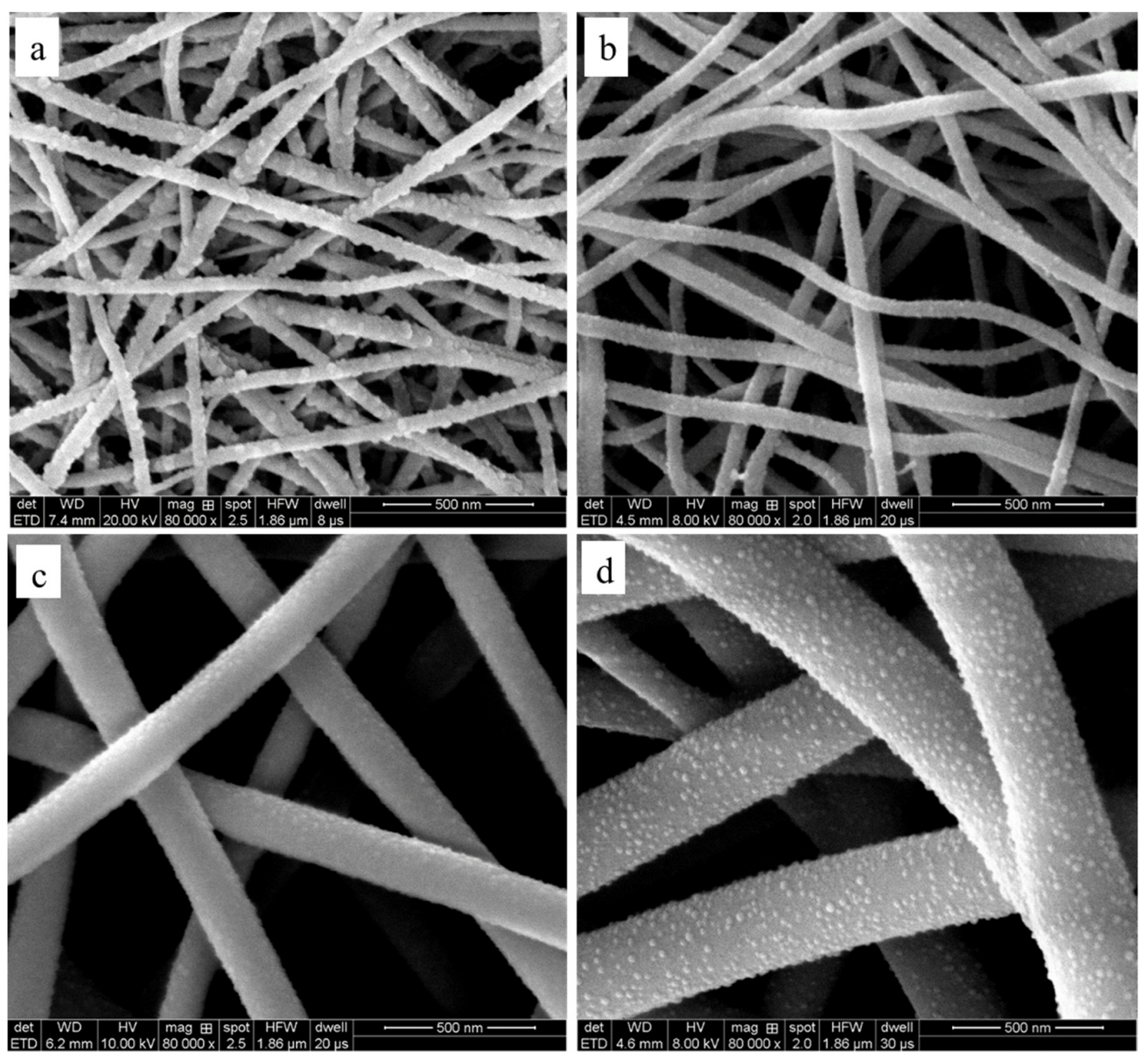

Figure 8. SEM images of the reduced catalysts made from the solution with different metal ion contents: (a) C10; (b) C20; (c) C30; (d) C40.

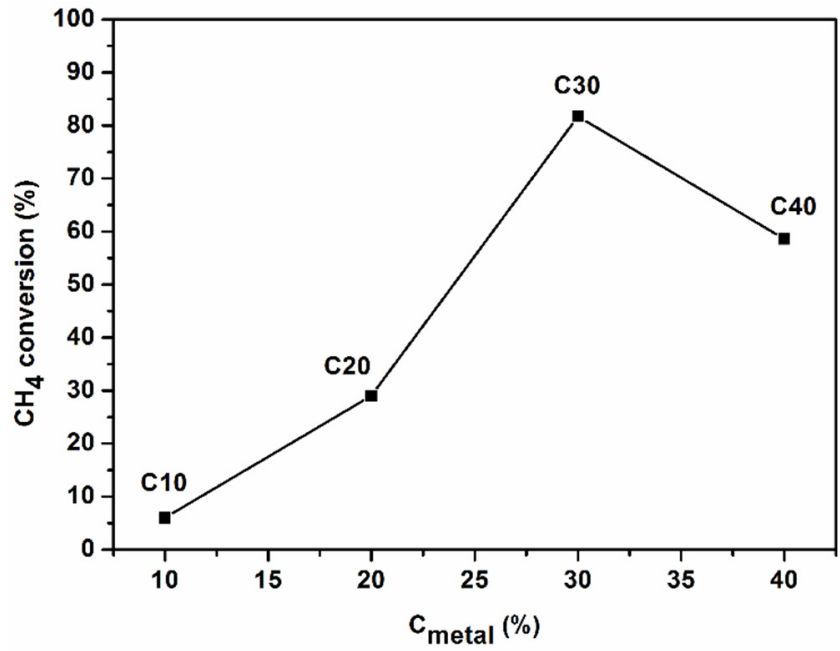

Figure 9. Methane conversion of the catalysts prepared with different metal ion contents during the POM for $10 \mathrm{~h}$ at $750{ }^{\circ} \mathrm{C}$ and a gas flow rate of $800 \mathrm{~mL} \mathrm{~min}^{-1}$.

The morphologies of the catalysts after 10 h-POM test are shown in Figure 10, and the fibrous structure was stable during reactions. The Ni particles on the C10 and C20 catalyst surface disappeared after the reaction due to $\mathrm{Ni}$ oxidation. In contrast, the Ni particles retained for the $\mathrm{C} 30$ and $\mathrm{C} 40$ catalysts while carbon fibers could be found. 

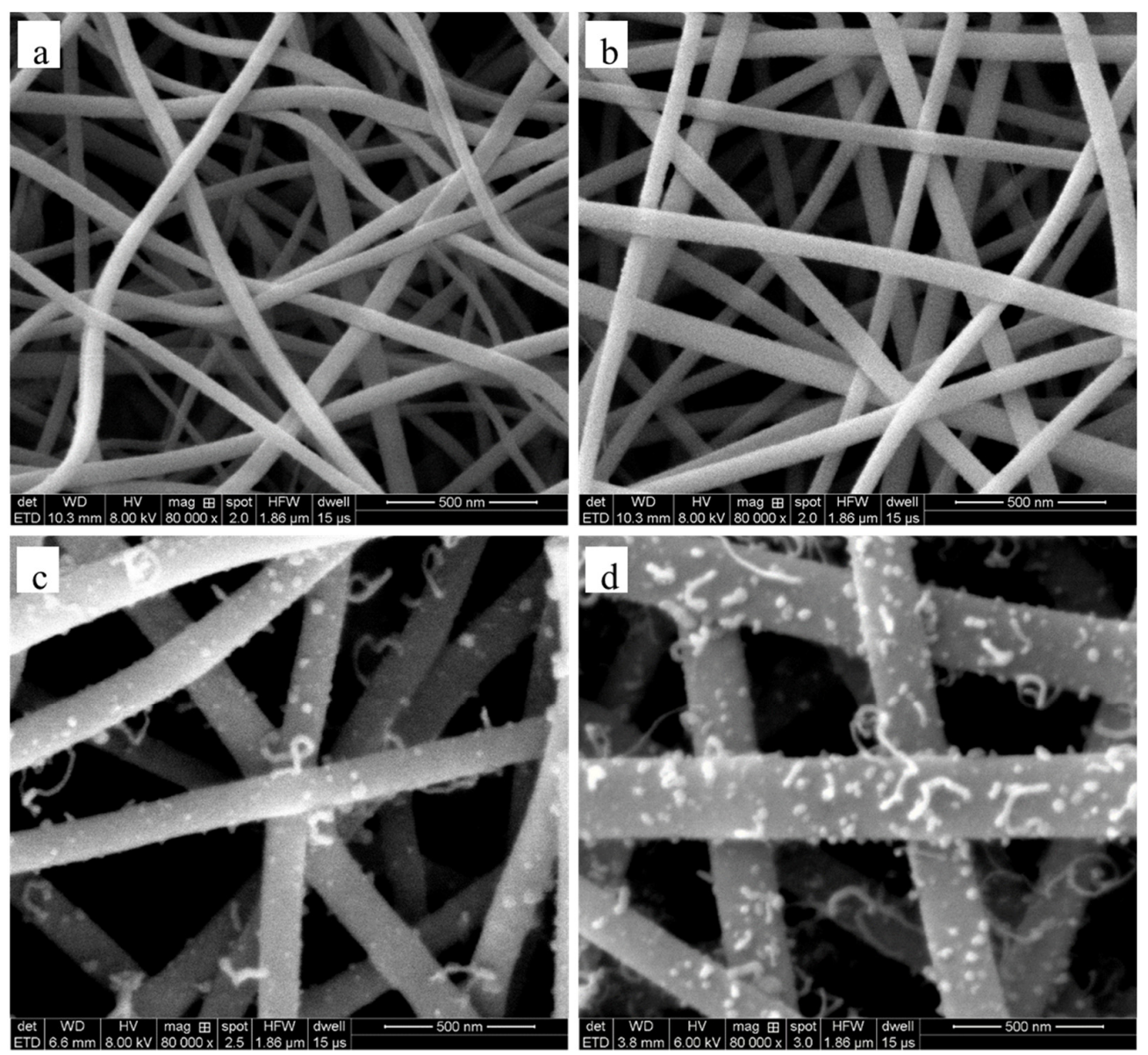

Figure 10. SEM images of the spent catalysts made from the solution with different metal ion contents:

(a) C10; (b) C20; (c) C30; (d) C40.

\subsection{Effect of Calcination Temperature}

$\mathrm{Ni}$ catalysts are formed via reducing $\mathrm{NiAl}_{2} \mathrm{O}_{4}$, and catalytic activity is affected by catalyst crystallinity, which is determined by calcination temperature. To study the effect of calcination temperature on catalytic activity, the fibrous catalysts were calcined at temperatures ranging from 700 to $900{ }^{\circ} \mathrm{C}$. All catalysts were prepared with a metal ion content of $30 \mathrm{wt} \%$ and the $\mathrm{H}_{2} \mathrm{O} / \mathrm{C}_{2} \mathrm{H}_{5} \mathrm{OH}$ solvent. As shown in Figure $11 \mathrm{a}, \mathrm{NiAl}_{2} \mathrm{O}_{4}$ has a low crystallinity when calcined at $700{ }^{\circ} \mathrm{C}$. With the increase of calcination temperature, the crystallinity is enhanced, resulting in the increase of crystal sizes. Accordingly, the reduced catalysts show the increased $\mathrm{Ni}$ crystal sizes with calcination temperature according to the diffraction intensity in Figure 11b. Calculated by the Scherrer equation, the Ni crystal sizes are 7.4, 8.1 and $9.2 \mathrm{~nm}$ at the calcination temperatures of 700,800 and $900{ }^{\circ} \mathrm{C}$, respectively.

TPR profiles are shown in Figure 12. According to the XRD results, $\mathrm{NiAl}_{2} \mathrm{O}_{4}$ crystallinity enhances with the increase of calcination temperature, resulting in the increase of reduction temperature. As shown in Figure 11a, Ni reducibility increases slightly due to the presence of $\mathrm{NiO}$ with the increase of calcination temperature. Additionally, the Ni dispersion of catalysts reduces with the increase of calcination temperature, which is attributed to the increase of Ni crystal size [6].

The POM was conducted at $750{ }^{\circ} \mathrm{C}$ and a gas flow rate of $800 \mathrm{~mL} \mathrm{~min}^{-1}$, and the methane conversions are shown in Figure 13. According to the TPR results in Figure 12, the catalysts calcined at 700,800 and $900{ }^{\circ} \mathrm{C}$ were reduced for $1 \mathrm{~h}$ at a reduction peak temperature of 615,750 and $800{ }^{\circ} \mathrm{C}$, respectively, which ensures that the catalysts were pre-reduced to the same extent. The catalyst calcined at the higher temperature showed the lower catalytic activity due to the decrease of Ni dispersion (Table 4). 

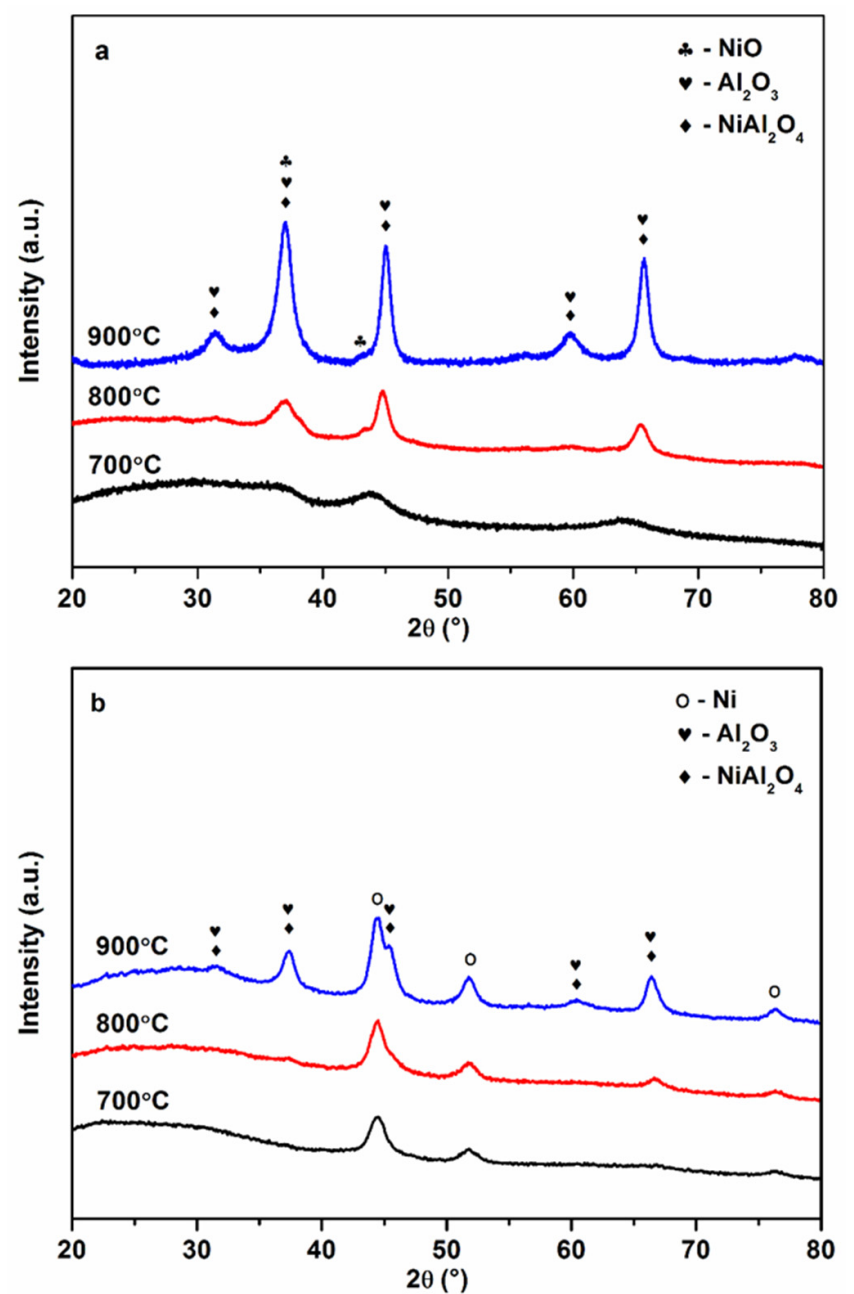

Figure 11. XRD patterns of the catalysts with different calcination temperatures: (a) Before reduction; (b) after reduction at $750{ }^{\circ} \mathrm{C}$ for $1 \mathrm{~h}$.

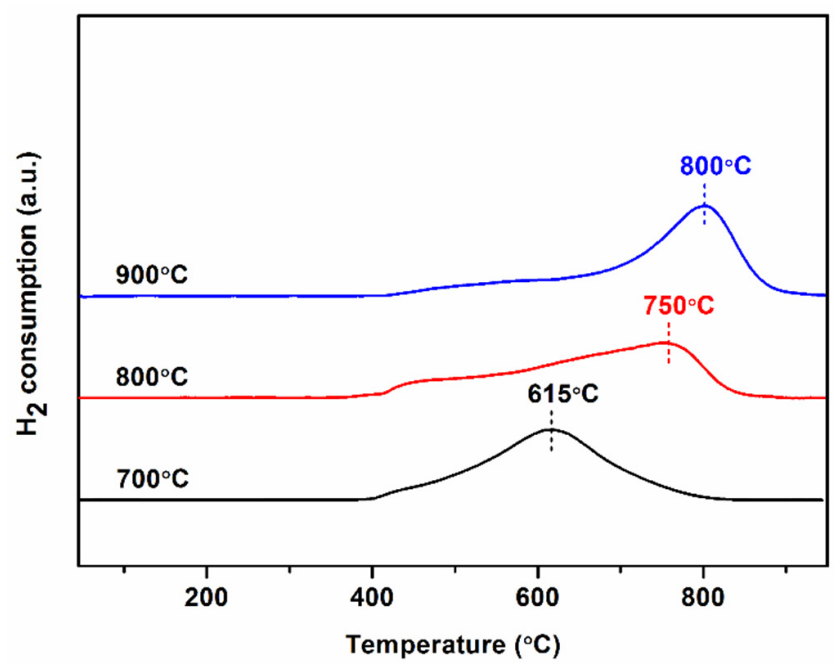

Figure 12. TPR profiles of the catalysts prepared at different calcination temperatures. 


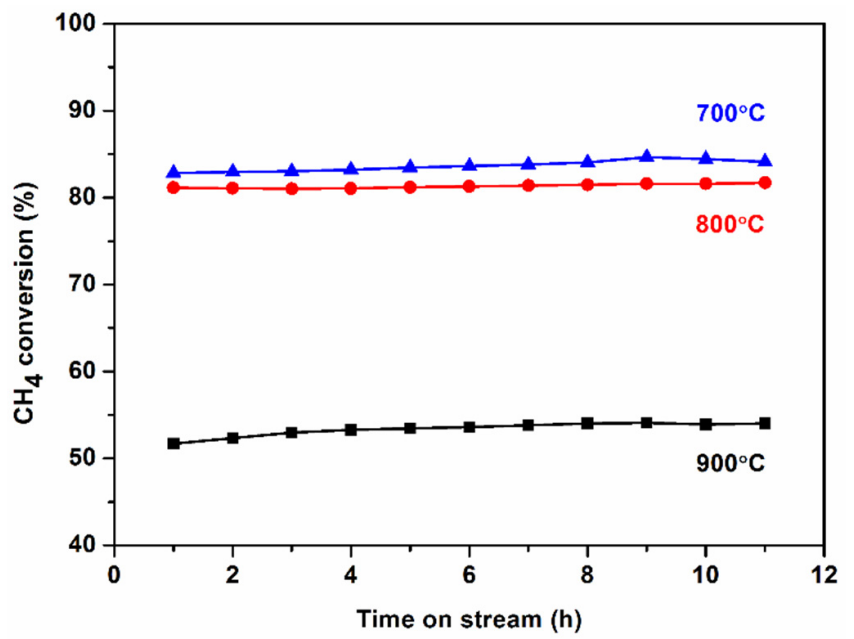

Figure 13. Methane conversion of the catalysts prepared at different calcination temperatures during the POM for $10 \mathrm{~h}$ at $750{ }^{\circ} \mathrm{C}$ and a gas flow rate of $800 \mathrm{~mL} \mathrm{~min}{ }^{-1}$.

Table 4. Reducibility and $\mathrm{Ni}$ dispersion of $\mathrm{Ni} / \mathrm{Al}_{2} \mathrm{O}_{3}$ catalysts.

\begin{tabular}{cccc}
\hline Temperature $\left({ }^{\circ} \mathbf{C}\right)$ & Peak Area & Reducibility (\%) & Ni Dispersion (\%) \\
\hline 700 & 50.8 & 81.7 & 0.63 \\
800 & 52.7 & 85.7 & 0.60 \\
900 & 55.5 & 91.5 & 0.38 \\
\hline
\end{tabular}

\subsection{Effect of Reaction Temperature and Gas Flow Rate}

The fibrous structure has high thermal stability and large void fraction, which makes it possible to operate at high temperatures and gas flow rates. The $\mathrm{C} 30$ catalyst was chosen to investigate the effect of reaction conditions on catalytic activity. Figure 14 shows that $\mathrm{CH}_{4}$ conversion increases with reaction temperature at a gas flow rate of $1000 \mathrm{~mL} \mathrm{~min}^{-1}$, and the catalytic reaction rate increases with gas flow rate at $750{ }^{\circ} \mathrm{C}$. Under the reaction conditions of $800{ }^{\circ} \mathrm{C}$ and a flow rate of $1000 \mathrm{~mL} \mathrm{~min}^{-1}$, the selectivity of $\mathrm{H}_{2}$ and $\mathrm{CO}$ was $97 \%$ and $87 \%$, respectively, and the yield was $9.8 \times 10^{5} \mathrm{~L} \mathrm{Kg}^{-1} \mathrm{~h}^{-1}$ and $4.4 \times 10^{5} \mathrm{~L} \mathrm{Kg}^{-1} \mathrm{~h}^{-1}$, respectively. The $\mathrm{H}_{2}$ and $\mathrm{CO}$ yields were calculated according to $\mathrm{H}_{2}$ and $\mathrm{CO}$ amounts in the product gas. Therefore, the fibrous $\mathrm{Ni} / \mathrm{Al}_{2} \mathrm{O}_{3}$ catalyst can generate high syngas yields owing to the fibrous structure.

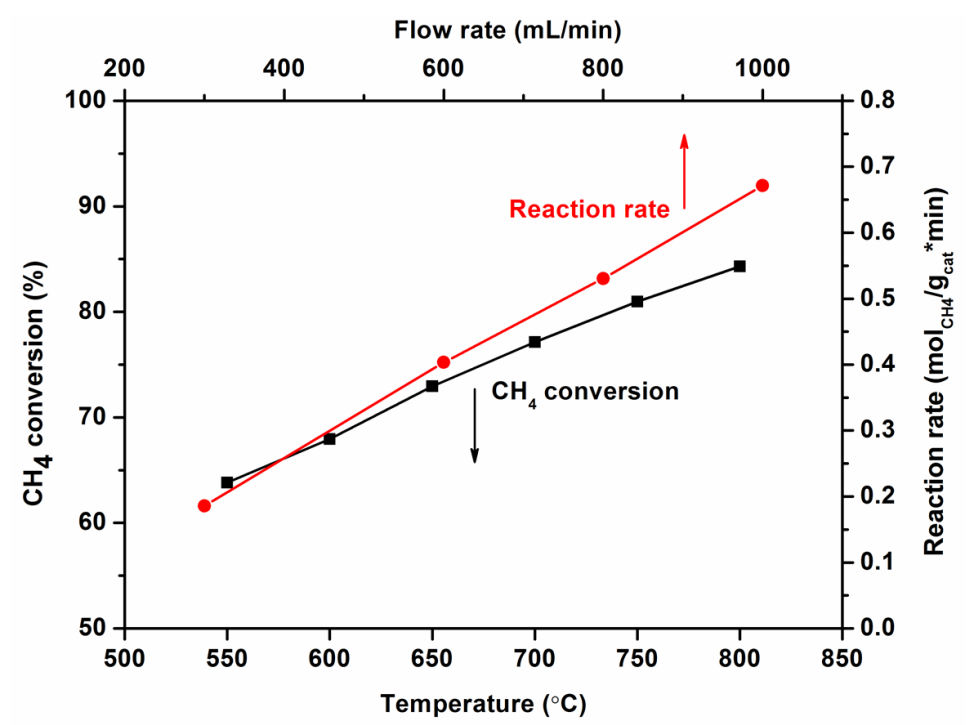

Figure 14. Catalytic performance of the $\mathrm{C} 30$ catalyst during the POM changing with operation temperature and gas flow rate. 


\section{Conclusions}

In this study, the effects of preparation parameters on catalyst properties were investigated on electrospun fibrous $\mathrm{Ni} / \mathrm{Al}_{2} \mathrm{O}_{3}$ catalysts. The catalyst prepared with the $\mathrm{H}_{2} \mathrm{O} / \mathrm{C}_{2} \mathrm{H}_{5} \mathrm{OH}$ solvent mainly consisted of $\mathrm{NiAl}_{2} \mathrm{O}_{4}$, while the catalyst prepared with the $\mathrm{DMF} / \mathrm{C}_{2} \mathrm{H}_{5} \mathrm{OH}$ solvent formed $\mathrm{NiO}$ due to $\mathrm{Ni}$ segregation. The catalytic performance is mainly contributed by the $\mathrm{Ni}$ from $\mathrm{NiAl}_{2} \mathrm{O}_{4}$ reduction, and therefore the catalytic activity of the catalyst prepared with the $\mathrm{H}_{2} \mathrm{O} / \mathrm{C}_{2} \mathrm{H}_{5} \mathrm{OH}$ solvent was higher than that of the catalyst prepared with the $\mathrm{DMF} / \mathrm{C}_{2} \mathrm{H}_{5} \mathrm{OH}$ solvent. The metal ion content affects catalyst composition, microstructure, reducibility and dispersion and therefore catalytic performance during the POM. The C 30 catalyst had the highest catalytic performance. In addition, the higher calcination temperature produced the larger $\mathrm{Ni}$ particles due to the larger crystal size of $\mathrm{NiAl}_{2} \mathrm{O}_{4}$, which required a high reduction temperature. Therefore, the catalytic activity during the POM decreased with the increase of calcination temperature. Finally, it has been confirmed that the fibrous $\mathrm{Ni} / \mathrm{Al}_{2} \mathrm{O}_{3}$ catalysts can achieve high syngas yields through the POM owing to the fibrous structure.

Author Contributions: Conceptualization, Y.M. (Yuyao Ma) and D.D.; methodology, Y.M. (Yuyao Ma), Y.M. (Yuxia Ma), M.L. and Y.C.; software, Y.M. (Yuyao Ma); validation, X.H., Z.Y. and D.D.; formal analysis, Y.M. (Yuyao Ma), Y.M. (Yuxia Ma) and D.D.; investigation, Y.M. (Yuyao Ma), Y.M. (Yuxia Ma), M.L. and Y.C.; resources, D.D.; data curation, Y.M. (Yuyao Ma), M.L. and Y.C.; writing-original draft preparation, Y.M. (Yuyao Ma); writing-review and editing, D.D.; visualization, X.H., Z.Y. and D.D.; supervision, X.H., Z.Y. and D.D.; project administration, D.D.; funding acquisition, D.D.

Funding: This research was funded by Natural Science Foundation of Shandong Province (ZR2017MEM022) and Shandong Province Key Research and Development Program (2018GGX102037).

Acknowledgments: D. H. Dong acknowledges the startup funding provided by the University of Jinan. The study is a part of the projects of Natural Science Foundation of Shandong Province (ZR2017MEM022) and Shandong Province Key Research and Development Program (2018GGX102037).

Conflicts of Interest: The authors declare no conflict of interest. The funder played a decisive role in the design of the study; in the collection, analyses or interpretation of data; in the writing of the manuscript and in the decision to publish the results.

\section{References}

1. Wang, Z.; Cheng, Y.; Shao, X.; Veder, J.P.; Hu, X.; Ma, Y.; Wang, J.; Xie, K.; Dong, D.; Jiang, S.P.; et al. Nanocatalysts anchored on nanofiber support for high syngas production via methane partial oxidation. Appl. Catal. A 2018, 565, 119-126. [CrossRef]

2. Dai, Y.; Liu, W.; Formo, E.; Sun, Y.; Xia, Y. Ceramic nanofibers fabricated by electrospinning and their applications in catalysis, environmental science, and energy technology. Polym. Adv. Technol. 2011, 22, 326-338. [CrossRef]

3. Lasprilla-Botero, J.; Álvarez-Láinez, M.; Lagaron, J.M. The influence of electrospinning parameters and solvent selection on the morphology and diameter of polyimide nanofibers. Materi. Today Commun. 2018, 14, 1-9. [CrossRef]

4. Bhardwaj, N.; Kundu, S.C. Electrospinning: A fascinating fiber fabrication technique. Biotechnol. Adv. 2010, 28, 325-347. [CrossRef] [PubMed]

5. Thavasi, V.; Singh, G.; Ramakrishna, S. Electrospun nanofibers in energy and environmental applications. Energy Environ. Sci. 2008, 1, 205-221. [CrossRef]

6. Wang, Z.; Hu, X.; Dong, D.; Parkinson, G.; Li, C.Z. Effects of calcination temperature of electrospun fibrous $\mathrm{Ni} / \mathrm{Al}_{2} \mathrm{O}_{3}$ catalysts on the dry reforming of methane. Fuel Process. Technol. 2017, 155, 246-251. [CrossRef]

7. Liu, L.; Wang, S.; Guo, Y.; Wang, B.; Rukundo, P.; Wen, S.; Wang, Z.-J. Synthesis of a highly dispersed $\mathrm{Ni} / \mathrm{Al}_{2} \mathrm{O}_{3}$ catalyst with enhanced catalytic performance for $\mathrm{CO}_{2}$ reforming of methane by an electrospinning method. Int. J. Hydrog. Energy 2016, 41, 17361-17369. [CrossRef]

8. Goetsch, D.A.; Schmidt, L.D. Microsecond catalytic partial oxidation of alkanes. Science 1996, 271, $1560-1562$. [CrossRef]

9. Hickman, D.A.; Schmidt, L.D. Production of syngas by direct catalytic-oxidation of methane. Science 1993, 259, 343-346. [CrossRef] [PubMed] 
10. Reichelt, E.; Heddrich, M.P.; Jahn, M.; Michaelis, A. Fiber based structured materials for catalytic applications. Appl. Catal. A 2014, 476, 78-90. [CrossRef]

11. Sahli, N.; Petit, C.; Roger, A.C.; Kiennemann, A.; Libs, S.; Bettahar, M. Ni catalysts from $\mathrm{NiAl}_{2} \mathrm{O}_{4}$ spinel for $\mathrm{CO}_{2}$ reforming of methane. Catal. Today 2006, 113, 187-193. [CrossRef]

12. Jiménez-González, C.; Boukha, Z.; De Rivas, B.; Delgado, J.J.; Cauqui, M.Á.; González-Velasco, J.R.; Gutiérrez-Ortiz, J.I.; López-Fonseca, R. Structural characterisation of Ni/alumina reforming catalysts activated at high temperatures. Appl. Catal. A 2013, 466, 9-20. [CrossRef]

13. Li, C.; Chen, Y.W. Temperature-programmed-reduction studies of nickel oxide/alumina catalysts: Effects of the preparation method. Thermochim. Acta 1995, 256, 457-465. [CrossRef]

14. Ma, Y.; Ma, Y.; Zhao, Z.; Hu, X.; Ye, Z.; Yao, J.; Buckley, C.E.; Dong, D. Comparison of fibrous catalysts and monolithic catalysts for catalytic methane partial oxidation. Renew. Energy 2019, 138, 1010-1017. [CrossRef]

C 2019 by the authors. Licensee MDPI, Basel, Switzerland. This article is an open access article distributed under the terms and conditions of the Creative Commons Attribution (CC BY) license (http://creativecommons.org/licenses/by/4.0/). 